Publisher: ROYAL SOC CHEMISTRY, THOMAS GRAHAM HOUSE, SCIENCE PARK, MILTON RD,, CAMBRIDGE CB4 OWF, CAMBS, ENGLAND

Subject Category: Chemistry, Analytical

IDS Number: 450ZW

ISSN: 0003-2654

http://www.rsc.org/publishing/journals/AN/article.asp?doi=b102185k

\title{
TWO-PARAMETER DETERMINATION IN VINEGAR BY A FLOW INJECTION-PERVAPORATION SYSTEM
}

\author{
J. González-Rodríguez ${ }^{1}$, P. Pérez-Juan ${ }^{1}$ and M.D. Luque de Castro ${ }^{2}$ * \\ ${ }^{1}$ R\&D Department Pérez Barquero, S.A. Avda. de Andalucía, 27, E-14550, \\ Montilla, Córdoba, Spain. Fax: 957 650208, E-mail: barquero@,fiab.es \\ ${ }^{2}$ Analytical Chemistry Division, Campus of Rabanales. Annex C-3 Córdoba. \\ Spain. Fax: 34-957-218615, E-mail: qa1lucam@uco.es
}

A flow-injection method (FI) for the sequential determination of ethanol and acetic acid in vinegar is reported. The determination of ethanol is based on the oxidation of the pervaporated ethanol by $\mathrm{Cr}_{2} \mathrm{O}_{7} \mathrm{~K}_{2}$. The acetic acid is determined by an acid-base reaction with Thymol Blue as the indicator. Both reactions are monitored photometrically at $600 \mathrm{~nm}$ using a single detector. Optimisation studies and assessment of the sequential FI method are also reported. The linear determination range is between $0-12 \%(\mathrm{v} / \mathrm{v})$ for ethanol and $0-10 \%$ (grams of acetic acid in 100 $\mathrm{ml}$ ) for acetic acid. The sample throughput of the sequential manifold is 7 per hour. The new method has been applied to vinegar samples and the results obtained are in excellent agreement with those from the reference methods used in Spain.

Keywords: ethanol, acetic acid, flow injection, pervaporation, photometry, vinegar 


\section{Introduction}

The Food and Agriculture Organisation /World Health Organisation (FAO/ WHO) defines vinegar as a liquid fit for human consumption exclusively produced from agricultural raw material, containing starch and sugars by a double alcoholic and acetic fermentation process. ${ }^{1}$

There are many kinds of vinegar according to the raw material used in its production. The European legislation allows eight different sources to be used, namely: wine, fruits, cider, alcohol distilled from agricultural material, cereals, malt, honey and buttermilk. $^{2}$

The main constituent of vinegar is acetic acid, whatever the raw substrate. It is expressed in acetic degree (grams of acetic acid per 100 millilitres of vinegar) at $20^{\circ} \mathrm{C}$. In the Spanish legislation $^{3}$, the total acidity of vinegar expressed in acetic acid must not be lower than $50 \mathrm{~g} / \mathrm{l}$, except for wine vinegar, which must be at least $60 \mathrm{~g} \mathrm{l}^{-1}$.

Industrial production of vinegar from ethanol tries to obtain the highest amount of the final product, but is not recommendable to lead the process to exhaustion because acetic bacteria in the absence of their substrate can degrade acetic acid to $\mathrm{CO}_{2}$ and $\mathrm{H}_{2} \mathrm{O}$. Thus, a residual alcohol content lower than $1 \%(\mathrm{v} / \mathrm{v})$ can be found in industrial processes, whereas in traditional production of vinegar from wine the residual alcohol level is 2-3\%(v/v). This alcohol combines with organic acids to yield esters which endow vinegar with the characteristic flavour and smell.

Ethanol and acetic acid values are frequently monitored during the overall acetic fermentation process. Traditional methods for analysing these parameters consist of, (a) for ethanol, distillation of ethanol, addition of a given volume of a standard solution of potassium dichromate and back titration of the excess of this reagent, ${ }^{4}$ and (b) for acetic acid, direct titration with sodium hydroxide in the presence of phenolphthalein. ${ }^{5}$ Both are time-consuming methods.

Alternative methods based on flow injection analysis for measurement of acetic acid content in vinegars are scarce. Gama et al. ${ }^{6}$ developed a method for this analyte using an antimony electrode, with sufficient precision for routine analysis. Schügerl et $\mathrm{al}^{7}$ implemented a flow injection on-line enzymatic method based on sarcosine oxidase for the determination of acetate, but it was not used for vinegar. Another approach to the determination of total acidity of vinegars was developed by Cardwell et al. ${ }^{8}$ using discontinuous flow analysis and photometric end-point detection, and Honorato et al. proposed a monosegmented flow titration with spectrophotometric detection. ${ }^{9}$

Flow injection methods for the determination of ethanol widely applied in wines, can be divided according to the presence or absence of a prior separation of the analyte, or the use of an enzymatic or chemical derivatisation reaction. Most non-enzymatic methods 
show a linear ranges of ethanol concentration higher that those existing in vinegars, which make them inapplicable for this purpose. There are no enzymatic methods in the literature for the determination of ethanol in vinegar.

In this work a continuous, flow injection method which integrates a pervaporation module for the sequential determination of ethanol and acetic acid was developed. Analytical pervaporation $^{10,11}$ permits the removal of ethanol from vinegar while acetic acid is determined without the help of any separation step. No similar, sequential or simultaneous, systems for these parameters have been reported previously.

\section{Experimental}

\section{Apparatus and instruments}

The manifold used is shown in Fig.1. It was built using a four-channel Gilson Minipuls-3 peristaltic pump (Villiers le Bel, France), fitted with a rate selector; three Rheodyne 5041 injection valves (Elkay, Galway, Ireland), one of them used as selecting valve, and PTFE tubing of $0.5 \mathrm{~mm}$ i.d. (Scharlau, Barcelona, Spain). A Philips PU8625 UV-visible spectrophotometer (Philips, Cambridge, U.K.), equipped with a Hellma 138-QS flow-cell (Hellma, Jamaica, NY) and a Knauer recorder (Scharlau) was also used.

A Selecta Tectrom bio water-bath (Barcelona, Spain), a laboratory-made pervaporation module, described elsewhere ${ }^{9,10}$ and PTFE membranes of 47 $\mathrm{mm}$ diameter and $1.5 \mathrm{~mm}$ thickness from Trace (Braunschweig, Germany) were used. Measurements of acetic acid were made with a Crison (Barcelona, Spain) Compact Titrator D, mod. D-33.

\section{Reagents and solutions}

Standard solutions both for optimisation studies and calibration were prepared from acetic acid and absolute ethanol, both from Panreac (Barcelona, Spain).

For the proposed method, the acceptor stream of the pervaporation module was an aqueous solution of $46 \mathrm{~g}$ $\mathrm{I}^{-1}$ potassium dichromate and $8,5 \mathrm{M}$ sulphuric acid both from Panreac. The indicator-buffer solution consisted of a $0,2 \mathrm{M}$ aqueous solution of potassium chloride (Panreac), $0,25 \mathrm{M}$ or $0,5 \mathrm{M}$ of sodium hydroxide (Panreac) and $9 \times 10^{-5}$ $\mathrm{M}$ of Thymol Blue (Merck, Darmstadt, Germany), adjusted to $\mathrm{pH} 12,5$.

For the official method for ethanol in vinegar, ${ }^{3}$ an aqueous solution of $33,608 \mathrm{~g} \mathrm{l}^{-1}$ of potassium dichromate (Panreac), $135 \mathrm{~g} \mathrm{l}^{-1}$ of ammonium iron (II) sulphate hexahydrate (Panreac) in $0,4 \mathrm{M}$ of sulphuric acid (Panreac), an aqueous solution 9,5 $\mathrm{M}$ sulphuric acid (Panreac), aqueous solution of $6,95 \mathrm{~g}^{-1}$ iron(II) sulphate heptahydrate with $14,85 \mathrm{~g} \mathrm{l}^{-1}$ of 1,10-phenantroline used as indicator, and a $4 \mathrm{M}$ solution calcium hydroxide were used.

The reference method used for determining acetic acid in vinegar required a $0,1 \mathrm{~N}$ standardised solution of sodium hydroxide (Panreac). 


\section{Reference procedures}

The reference procedure in Spanish cellars for the determination of ethanol in vinegar is based on the photometric detection of $\mathrm{Cr}^{+3}$ at $600 \mathrm{~nm}$, formed by oxidation of ethanol after distillation of the vinegar. ${ }^{4}$ Sodium hydroxide was added to $200 \mathrm{ml}$ of vinegar up to $\mathrm{pH}$ 10-11 and then distilled and collected in a $100 \mathrm{ml}$ flask. A $20 \mathrm{ml}$ volume of diluted sulphuric acid and $20 \mathrm{ml}$ of potassium dichromate were added to 10 $\mathrm{ml}$ of distillate and the mixture was allowed to stand for $30 \mathrm{~min}$. The excess of potassium dichromate was titrated with ammonium iron(II) sulphate in the presence of 1,10-phenantroline.

The reference method used for the determination of acetic acid in vinegar samples was based on titration with 0,1 $\mathrm{M}$ sodium hydroxide using an automated potentiometric titrator.

\section{Proposed method}

Figure 1 shows the manifold used for the sequential determination. The sample was introduced into the loops of the injection valves, $I V_{1}$ and $\mathrm{IV}_{2}$, by aspiration. First, the content of $\mathrm{IV}_{1}$ was injected into a stream of water and led to the donor chamber of the pervaporation unit, after mixing with an aqueous buffer solution of sodium hydroxide, potassium chloride and Thymol Blue. The indicator showed whether the $\mathrm{pH}$ of the solution was $>8$. The ethanol was pervaporated and collected in the acceptor solution containing potassium dichromate and sulphuric acid. The pervaporated ethanol was oxidised and the $\mathrm{Cr}^{+3}$ formed driven to the spectrophotometer and monitored at $600 \mathrm{~nm}$. After the maximum absorbance signal had been reached, $\mathrm{IV}_{3}$ was switched and the channel from $\mathrm{R}_{2}$ was selected; thus, the new baseline for the acetic acid determination was established. Then, sample in the loop of $\mathrm{IV}_{2}$ was introduced into the carrier stream (water) which flowed parallel to the pervaporation unit and merged with a buffer stream of indicator. The change in the colour of the resulting stream was

\section{Pervaporator}

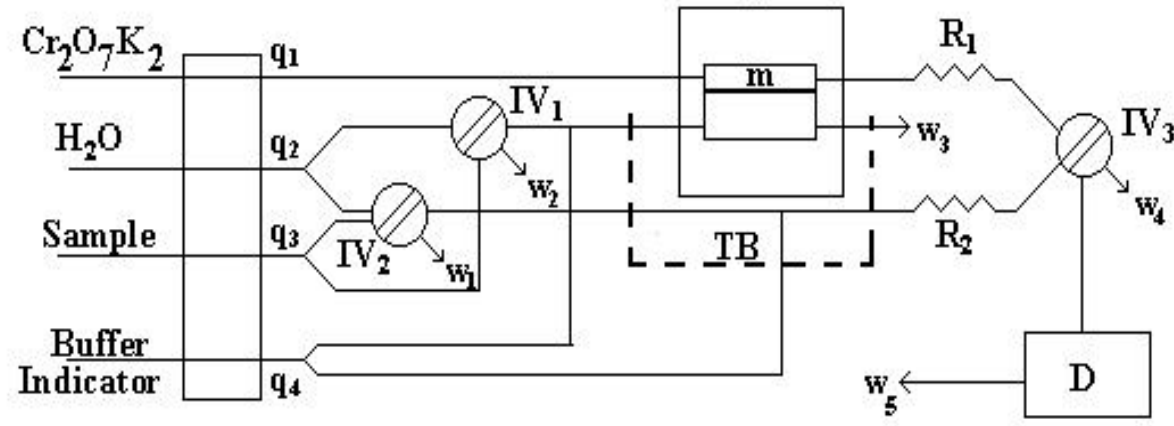

Figure 1. Manifold for the sequential determination of ethanol and acetic acid in vinegar: $q=$ flow rate, $\mathrm{IV}_{1}$ and $\mathrm{IV}_{2}=$ injection valves, $\mathrm{IV}_{3}=$ selection valve, $\mathrm{m}=$ membrane, $\mathrm{w}=$ waste, $\mathrm{TB}=$ thermostatic bath, $\mathrm{R}=$ reactor, $\mathrm{D}=$ detector. 
monitored photometrically at $600 \mathrm{~nm}$. After the maximum absorbance had been obtained, $\mathrm{IV}_{3}$ was turned again to establish the baseline for a new determination of ethanol.

\section{Results and discussion}

An optimisation study of the variables affecting each individual method was carried out using both the univariate and multivariate methods as required depending on the interdependence of the variables. The range over which the variables were studied and the optimum values found are given in Table 1.

\section{Optimisation of the method for the} determination of ethanol

Variables such as the concentration of $\mathrm{K}_{2} \mathrm{Cr}_{2} \mathrm{O}_{7}$ and that of $\mathrm{H}_{2} \mathrm{SO}_{4}$, and as the flow-rate and temperature were studied using a multivariate approach.

The concentration of $\mathrm{K}_{2} \mathrm{Cr}_{2} \mathrm{O}_{7}$ and $\mathrm{H}_{2} \mathrm{SO}_{4}$ in the acceptor stream were studied in the range 15-60 $\mathrm{g} \mathrm{l}^{-1}$ and 370$900 \mathrm{~g} \mathrm{l}^{-1}$, respectively, and plotted versus the absorbance (Fig. 2). These variables were studied in a previous work $^{12}$ and the optimum values found there were used as the starting point for this optimisation study. The signal increased with increasing concentration of $\mathrm{K}_{2} \mathrm{Cr}_{2} \mathrm{O}_{7}$ and $\mathrm{H}_{2} \mathrm{SO}_{4}$ approximately in the same ratio, but at a high concentration potassium dichromate precipitated. Concentrations of $46 \mathrm{~g} \mathrm{l}^{-1}$ potassium dichromate and $830 \mathrm{~g} \mathrm{l}^{-1}$ sulphuric acid were selected as a compromise between absorbance and reagent consumption.
The flow rates $\mathrm{q}_{1}$ and $\mathrm{q}_{2}$ in Fig. 1 (corresponding to the acceptor and donor streams, respectively) were set at the same value in order to avoid membrane deformation, and this common value was changed between $0,8-1,8 \mathrm{ml}$ $\min ^{-1}$. The flow rate for $\mathrm{q}_{3}$ was the same as for $\mathrm{q}_{1}$ and $\mathrm{q}_{2}$. Fig. 3 shows the surface obtained on plotting the flow rate and temperature versus the absorbance.

Table 1. Optimisation of variables

\begin{tabular}{lll}
\hline Variable & $\begin{array}{l}\text { Tested } \\
\text { range }\end{array}$ & $\begin{array}{l}\text { Optimum } \\
\text { value }\end{array}$ \\
\hline Chemical- & & \\
$\mathrm{K}_{2} \mathrm{Cr}_{2} \mathrm{O}_{7}\left(\mathrm{~g}^{-1}\right)$ & $15-60$ & 46 \\
$\mathrm{H}_{2} \mathrm{SO}_{4}\left(\mathrm{~g} \mathrm{l}^{-1}\right)$ & $370-900$ & 830 \\
$\mathrm{NaOH}(\mathrm{M})$ & $0,1-0,75$ & 0,25 and 0,5 \\
Thymol Blue & - & $9 \times 10^{-5}$ \\
$(\mathrm{M})$ & & \\
$\mathrm{KCl}(\mathrm{M})$ & - & 0,2 \\
$\mathrm{pH}$ buffer & $10-13$ & 12,5 \\
& & \\
FI- & & \\
$\mathrm{q}_{1}=\mathrm{q}_{2}=\mathrm{q}_{3}(\mathrm{ml}$ & $0,8-1,8$ & 1,6 \\
$\left.\mathrm{~min}^{-1}\right)$ & & \\
$\mathrm{q}_{4}\left(\mathrm{ml} \mathrm{min}{ }^{-1}\right)$ & $0,8-1,6$ & 1,2 \\
$\mathrm{IV}_{1}(\mathrm{ml})$ & $1-2$ & 2 \\
$\mathrm{IV}_{2}(\mu \mathrm{l})$ & $25-100$ & 40 \\
$\mathrm{R}_{1}(\mathrm{~cm})$ & $0-75$ & 50 \\
$\mathrm{R}_{2}(\mathrm{~cm})$ & $0-75$ & 40 \\
& & \\
Pervaporation - & & \\
$\left.\mathrm{T}^{(}{ }^{\circ} \mathrm{C}\right)$ & $40-90$ & 80 \\
\hline
\end{tabular}

The temperature is a more influential parameter than the flow rate. The highest absorbance values were obtained at low flow rates and high temperature. The temperature had a 


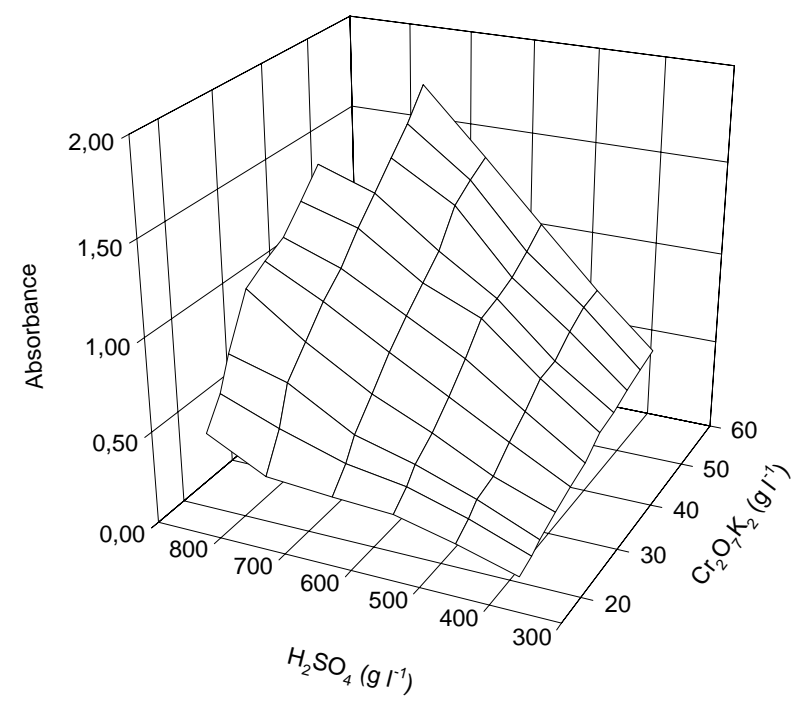

Figure 2. Evolution of absorbance versus dichromate and sulphuric concentrations for the optimisation of ethanol.

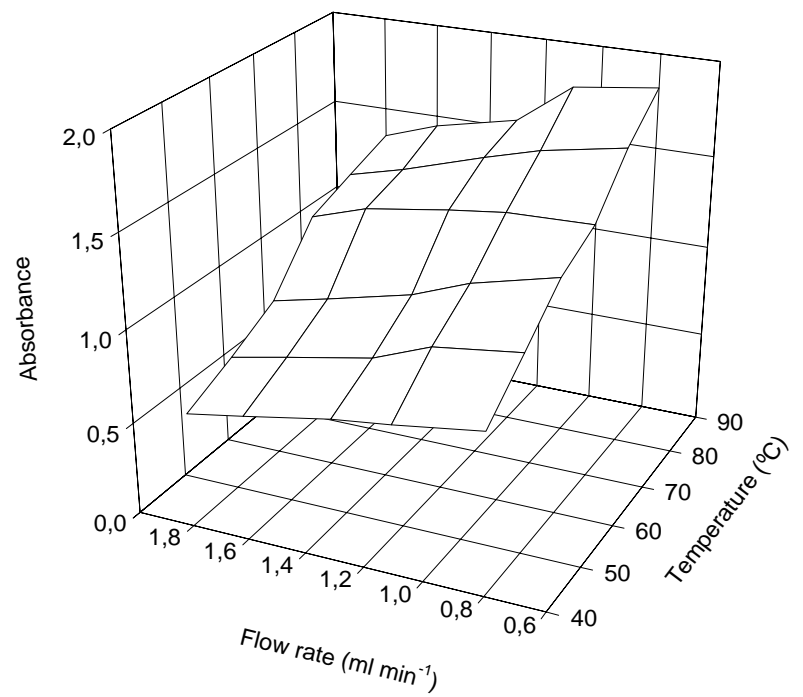

Figure 3. Evolution of absorbance versus flow rate and temperature for the optimisation of ethanol. 
marked influence on the efficiency of the pervaporation process by increasing the vapour pressure of the analyte and, therefore, increasing the mass transfer through the membrane. The range 40$90{ }^{\circ} \mathrm{C}$ was tested. A temperature of 80 ${ }^{\circ} \mathrm{C}$ and a flow rate of $1,6 \mathrm{ml} \mathrm{min}{ }^{-1}$ were selected as a compromise between absorbance and sampling frequency.

The analytical signal was higher with increased injection volumes. The range tested was from 1 to $2,5 \mathrm{ml}$ and a value of $2,0 \mathrm{ml}$ was selected as the analytical signal levelled off at higher values. The function of reactor $R_{1}$ was the homogenisation of the chemical reagents/pervaporated analyte before reaching the spectrophotometer. A length of $50 \mathrm{~cm}$ was sufficient for this purpose.

The amount of pervaporated ethanol during the passage of the injected sample through the lower chamber of the separation module was efficient to provide absorbance values between 0,3 and 1,6 for the concentration range of this analyte in vinegar. Hence preconcentration approaches consisting of stopping the acceptor solution for enrichment in the volatile compound were unnecessary.

The buffer-indicator stream of flow rate $\mathrm{q}_{4}$ was split and the channel which merged with that from $I_{1}$ had the function of leading the sample to basic $\mathrm{pH}$ prior to reaching the pervaporation unit in order to avoid evaporation of volatile compounds in their protonated form, such as formaldehyde and acetaldehyde. The presence of the indi- cator showed whether or not this purpose was achieved.

\section{Optimisation of the method for acetic acid}

The variables which affect the method for the determination of acetic acid were studied using the univariate approach because of the simplicity of both the chemical and dynamic systems. The most important parameters were the concentration of buffer and indicator. The type of buffer was taken from the literature ${ }^{13}$ and modified as required. For a hydroxide-chloride buffer with a fixed concentration of 0,2 $\mathrm{M}$ potassium chloride, the concentration of sodium hydroxide was varied in the range of $0,1-0,75 \mathrm{M}$. The wide range of acetic acid concentration during the fermentation process (from 0 to $10 \mathrm{~g}$ acetic acid per $100 \mathrm{ml}$ ) made necessary two concentrations of buffer in order to encompass the whole range without loss of linearity (namely those with 0,25 and $0,5 \mathrm{M} \mathrm{NaOH})$. The concentration of Thymol Blue was $9 \times 10^{-5} \mathrm{M}$, which provided changes of absorbance between 0,5 and 1,5 for a $\mathrm{q}_{4}$ of $1,2 \mathrm{ml} \mathrm{min}^{-1}$. The length of reactor $\mathrm{R}_{2}$ was tested from 0 to $75 \mathrm{~cm}$. Values longer than $50 \mathrm{~cm}$ did not change the analytical results. The injection volume was studied in the range $25-100 \mu$, and an optimum value of $40 \quad \mu l$ was obtained.

\section{Characterisation of the methods}

A preliminary calibration curve for each analyte was constructed separately, then calibration curves were 
constructed for both compounds sequentially using the same standard solutions, containing both analytes.

\section{Individual calibrations}

Six standards solutions for each analyte were prepared containing concentrations between 0 and $12 \%(\mathrm{v} / \mathrm{v})$ for ethanol and between 0 and $10 \%$ (grams of acetic acid in $100 \mathrm{ml}$ ) for acetic acid. In both cases injections in duplicate were made. Two linear ranges were found for ethanol, between $0-4 \%(\mathrm{v} / \mathrm{v})$ and $4-12 \% \quad(\mathrm{v} / \mathrm{v})$. Two calibration curves were constructed for acetic acid using two buffer solutions $(0,25 \mathrm{M}$ or $0,5 \mathrm{M} \mathrm{NaOH}$ ) depending on the acetic acid content, $0-5 \%$ and $5-10 \%$, respectively.

\section{Sequential calibration}

There was no interference from acetic acid in the determination of ethanol as the pervaporated acid is not oxidised by dichromate. Calibration curves for both acetic acid and ethanol were constructed using a series of six standards of ethanol-acetic acid mixtures with concentrations between $0-10 \% \quad(\mathrm{v} / \mathrm{v})$ and $0-12 \%$ (grams of acetic acid in 100 $\mathrm{ml}$ ), respectively. The standards with a higher ethanol concentration contained the smaller acetic acid contents as in natural samples. No statistically significant differences between the results of the individual and sequential calibration were found.

\section{Assessment of the proposed method}

Thirty different vinegars and acetic fermentation samples were used in the assessment study. Each datum was the average of three determinations. The protocol for assessment consisted of studying analytical parameters such as linearity range, traceability with a reference method, repeatability, reproducibility, detection and quantification limits and sample throughput.

\section{Repeatability (r)}

The Snedecor test $^{14}$ was applied in order to establish if the differences between the repeatability of the methods were significant. With this aim, the Fobs $=\mathrm{S}_{\mathrm{r}}{ }^{2} / \mathrm{S}_{\text {ref }}{ }^{2}$ was compared with the $\mathrm{F}_{1-\alpha}$ obtained from the Snedecor tables for $\alpha=0.05 \quad(\mathrm{P}=95 \%)$. As can be observed in Table 2, Fobs $<\mathrm{F}_{1-\alpha}$, so the repeatabilities of the FI and reference method are similar.

\section{Reproducibility (R)}

Table 2 shows the $\mathrm{R}$ values obtained and the results of the application of the Snedecor test: the reproducibility of the FI method is within the accepted range and similar to that of the reference method.

\section{Detection (LOD) and quantification (LQ) limits}

Table 2 shows that the best LOD corresponds to the FI method for ethanol measurements and both the reference and the FI method give similar values for acetic acid. Similar behaviour showed the quantification limits, that is, best LQ for the FI method for ethanol and similar LQs for acetic acid in both the official and FI methods. 


\section{Traceability}

The traceability of the method was studied by comparing the results obtained from 30 samples of different vinegars previously analysed by the reference method. Fig. 4 shows the regression of the flow injection method for acetic acid versus the reference method. The regression equation, $\mathrm{y}=$ $0,9436 \mathrm{x}+0,1142\left(\mathrm{r}^{2}=0,9947\right)$ shows a good correlation between the two methods. The correlation between the flow injection method and the reference method, in the case of ethanol, is also good and the regression equation is $\mathrm{y}=$ $1,0358 \times-0,0139\left(r^{2}=0,9930\right)$. Data dispersion is only observed for values upper to $8 \%(\mathrm{v} / \mathrm{v})$, which yields errors estimated in $\pm 0,7 \%$ (v/v) (see Fig. 5).

The confidence limits are shown in the figures in dotted lines. In both cases traceability was assured using the t-test.

\section{Sample throughput}

The results in Table 2 show that the FI method is the fastest for the individual determinations as compared with each the reference methods. The proposed sequential method (seven determinations per hour) cannot be compared with an official sequential counterpart because of the lack of the latter.

Table 2. Main analytical parameters

\begin{tabular}{|c|c|c|c|c|c|c|}
\hline \multirow{3}{*}{ Parameters $^{\mathrm{a}}$} & \multicolumn{6}{|l|}{ Methods } \\
\hline & \multicolumn{2}{|l|}{ Official } & \multicolumn{2}{|l|}{ FI } & \multicolumn{2}{|c|}{ Sequential F.I. } \\
\hline & Acidity & Alcohol & Acidity & Alcohol & Acidity & Alcohol \\
\hline Repeatability/g 1 ${ }^{-1}$ & 0,09 & 0,21 & 0,10 & (a) 0,24 & 0,11 & (a) 0,26 \\
\hline $\mathrm{S}_{\mathrm{r}} / \mathrm{g} \mathrm{l}^{-1}$ & 0,0323 & 0,0721 & 0,0363 & $\begin{array}{l}\text { (b) } 0,15 \\
\text { (a) } 0,090 \\
\text { (b) } 0,081\end{array}$ & 0,0373 & $\begin{array}{l}\text { (b) } 0,15 \\
\text { (a) } 0,093 \\
\text { (b) } 0,083\end{array}$ \\
\hline Reproducibility/ $\mathrm{g}^{-1}$ & 0,17 & 0,29 & 0,26 & $\begin{array}{l}\text { (a) } 0,29 \\
\text { (b) } 0,21\end{array}$ & 0,25 & $\begin{array}{l}\text { (a) } 0,31 \\
\text { (b) } 0,19\end{array}$ \\
\hline $\mathrm{S}_{\mathrm{R}} / \mathrm{g}^{-1}$ & 0,0623 & 0,091 & 0,052 & $\begin{array}{l}\text { (a) } 0,102 \\
\text { (b) } 0,095\end{array}$ & 0,055 & $\begin{array}{l}\text { (a) } 0,111 \\
\text { (b) } 0,101\end{array}$ \\
\hline Fobs $^{r}$ & - & - & 1,263 & $\begin{array}{l}\text { (a) } 1,56 \\
\text { (b) } 1,27\end{array}$ & 1,36 & $\begin{array}{l}\text { (a) } 1,66 \\
\text { (b) } 1,32\end{array}$ \\
\hline Fobs $^{R}$ & - & - & 0,697 & $\begin{array}{l}\text { (a) } 1,26 \\
\text { (b) } 1,09\end{array}$ & 0,78 & $\begin{array}{l}\text { (a) } 1,49 \\
\text { (b) } 1,23\end{array}$ \\
\hline$F_{1-\alpha}$ & - & - & 1,69 & 1,69 & 1,69 & 1,69 \\
\hline LOD & $0,008 \mathrm{~g} / 1$ & $0,02 \%$ & $0,009 \mathrm{~g} / 1$ & $0,005 \%$ & $0,008 \mathrm{~g} / 1$ & $0,009 \%$ \\
\hline LQ & $0,024 \mathrm{~g} / 1$ & $0,07 \%$ & $0,03 \mathrm{~g} / 1$ & $0,016 \%$ & $0,024 \mathrm{~g} / 1$ & $0,03 \%$ \\
\hline Sample throughput $/ \mathrm{h}^{-1}$ & 17 & 3 & 20 & 7 & 7 & \\
\hline
\end{tabular}

${ }^{a} S_{r}$ and $S_{R}$ are the deviation of repeatability and reproducibility, respectively. Fobs $=\mathrm{S}_{\mathrm{r}}{ }^{2} / \mathrm{S}_{\mathrm{ref}}{ }^{2} \cdot{ }^{\mathrm{b}}$ (a) usual range: from $1-4 \%$ (b) Fermentation range: $5-10 \%$ 


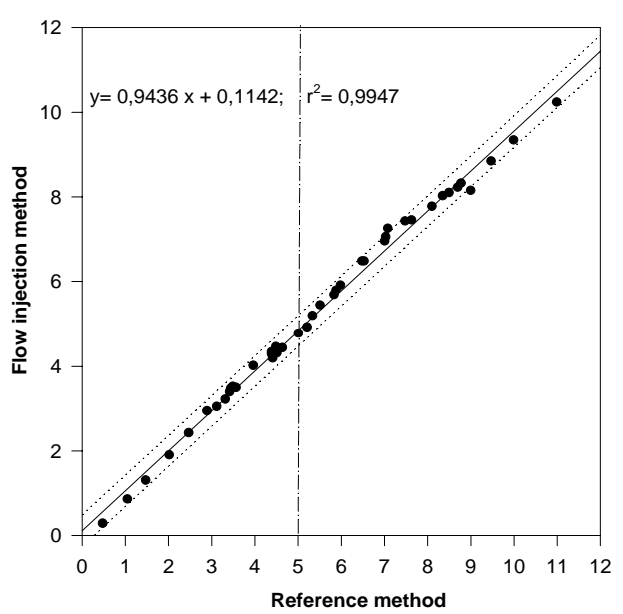

Figure 4. Correlation graph of the reference method versus the FI method for the determination of acetic acid. Dotted line shows the two linear calibration ranges used for the determinations. From 0-5\% corresponds to a buffer of $0,25 \mathrm{M} \mathrm{NaOH}$ and from $5-10 \%$ to a buffer of $0,5 \mathrm{M}$.

\section{Conclusions}

The proposed method permits the sequential determination of two major components of vinegar: acetic acid and ethanol. The method is simple, inexpensive, presents a good correlation with the official methods for these analytes and can be easily implemented in a cellar for monitoring acetic fermentation process. The use of pervaporation instead of gas diffusion offers the

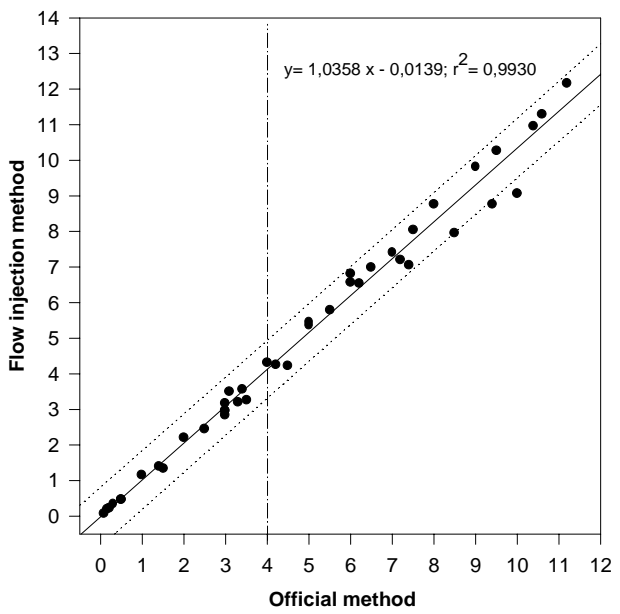

Figure 5. Correlation graphs of the reference method versus de FI method for the determination of ethanol. Dotted lines show the two linear ranges found for ethanol.

advantage of non sample-membrane contact, thus avoiding clogging and deterioration of the membrane.

Other advantages of the method reported here are both a sampling throughput higher than that of the methods which include a distillation step for separation of ethanol and absence of sample pretreatment.

This method constitutes a unique sequential application of flow injection for determinations in vinegar and offers the evident advantage of determining 
two parameters using the same manifold, thus reducing time and costs.

\section{Acknowledgements}

The Spanish Comisión Interministerial de Ciencia y Tecnología (CICyT) is thanked for financial support (Project BQM 2000/ 0241).

\section{References}

(1) $\mathrm{FAO} / \mathrm{WHO}$, Comission of the Codex Alimentarius, 16 ${ }^{\mathrm{a}}$ Sesión. Ginebra, 1985

(2) Regulation (EEC) 822/87, from the European Council, 16th March, 1987.

(3) Official Spanish Government Bulletin, Royal decree 2070/1993, B.O.E. $n^{\circ} 293$

(4) Recueil des méthodes Internationales d'Analyse des Vins et des Mouts, Office International de la vigne et $d u$ vin, O.I.V., Paris , France, 1990.

(5) A.O.A.C., Official Methods of Analysis, $11^{\mathrm{a}}$ Ed., p. 520, $\mathrm{n}^{\mathrm{o}}$ 30.068., 1970.

(6) M.D. Capelato, A. Marli dos Santos, O. Fatibello, O. Filho, R. Gama, Anal. Lett., 1996, 29, 711.

(7) M. Tservistas, B. Weigel, K. Schügerl, Anal. Chim. Acta, 1995, 316, 117.

(8) T.J. Cardwell, R.W. Cattrall, G.J. Cross, G.R. O'Connell, J.D. Petty, G.R. Scollary, Analyst, 1991, 116, 1051.

(9) R.S. Honorato, M.C.U. Araujo, G. Veras, E.A.G. Zagatto, R.A.S.
Lapa, J.L.F.C. Lima, Anal. Sci, 1999, 15, 665.

(10) I.L. Mattos, M.D. Luque de Castro, Anal. Chim Acta, 1994, 298, 159.

(11) I. Papaesftathiou, M.D. Luque de Castro, Anal. Chim. Acta, 1997, 354, 135.

(12) E. Mataix, M.D. Luque de Castro, Talanta, 2000, 51, 489.

(13) R.M.C. Dowson, Biochem. Research, 3rd Edition, Oxford, 1986.

(14) Recueil des méthodes Internationales d'Analyse des Vins et des Mouts, Annex A, Office International de la vigne et du vin, O.I.V., Paris , France, 1990. 
